\title{
Soluble NgR Fusion Protein Modulates the Proliferation of Neural Progenitor Cells via the Notch Pathway
}

\author{
Xin Li $\cdot$ Huanxing Su $\cdot$ Qing-Ling Fu $\cdot$ \\ Jiasong Guo $\cdot$ Daniel H. S. Lee $\cdot$ Kwok-Fai So $\cdot$ \\ Wutian Wu
}

Received: 15 June 2011 / Revised: 14 July 2011 / Accepted: 22 July 2011/Published online: 7 August 2011

(C) The Author(s) 2011. This article is published with open access at Springerlink.com

\begin{abstract}
NogoA, myelin-associated glycoprotein (MAG) and oligodendrocyte myelin glycoprotein are CNS myelin molecules that bind to the neuronal Nogo-66 receptor $(\mathrm{NgR})$ and inhibit axon growth. The NgR antagonist, soluble $\mathrm{NgR} 1-\mathrm{Fc}$ protein $(\mathrm{sNgR}-\mathrm{Fc})$, facilitates axon regeneration by neutralizing the inhibitory effects of myelin proteins in experimental models of CNS injury. Here we aim to investigate the effect of $\mathrm{sNgR}-\mathrm{Fc}$ on the
\end{abstract}

Xin Li, Huanxing Su, Qing-Ling Fu contributed equally to this work.

\section{Li}

Department of Emergency, The First Affiliated Hospital, Sun Yat-sen University, 58 Zhongshan II, Guangzhou 510080,

Guangdong, China

X. Li · H. Su · J. Guo · K.-F. So $(\bowtie) \cdot$ W. Wu $(\bowtie)$ Department of Anatomy and The State Key Laboratory of Brain and Cognitive Sciences, The University of Hong Kong,

21 Sassoon Road, Pokfulam, Hong Kong SAR, China

e-mail: hrmaskf@hkucc.hku.hk

W. Wu

e-mail:wtwu@hkucc.hku.hk

Q.-L. Fu

Otorhinolaryngology Hospital, The First Affiliated Hospital, Sun Yat-sen University, 58 Zhongshan Road II, Guangzhou 510080, Guangdong, China

D. H. S. Lee

Roche R\&D Center (China) Ltd, 720 Cai Lun Road, Building, Pudong 201203, Shanghai, China

\section{K.-F. So - W. Wu}

Joint Laboratory for Brain Function and Health (BFAH), Jinan University and The University of Hong Kong, Guangzhou, China proliferation of neural progenitor cells (NPCs). The hippocampus cells of embryonic rats were isolated and cultured in vitro. The expression of nestin, $\beta$ III-Tubulin, GFAP and Nogo-A on these cells was observed using immunocytochemistry. In order to investigate the effect on proliferation of NPCs, sNgR-Fc, MAG-Fc chimera and Notch1 blocker were added respectively. The total cell number for the proliferated NPCs was counted. BrdU was applied and the rate of proliferating cells was examined. The level of Notch1 was analyzed using Western blotting. We identified that NogoA is expressed in NPCs. sNgR-Fc significantly enhanced the proliferation of NPCs in vitro as indicated by BrdU labeling and total cell count. This proliferation effect was abolished by the administration of MAG suggesting specificity. In addition, we demonstrate that $\mathrm{sNgR}-\mathrm{Fc}$ is a potent activator for Notch1 and Notch1 antagonist reversed the effect of $\mathrm{sNgR}-\mathrm{Fc}$ on NPC proliferation. Our results suggest that $\mathrm{sNgR}-\mathrm{Fc}$ may modulate Nogo activity to induce NPC proliferation via the Notch pathway.

Keywords Nogo-66 receptor - Rat neural progenitor cells $\cdot$ Notch1 $\cdot$ NogoA $\cdot$ Myelin-associated glycoprotein

\section{Introduction}

Neural progenitor cells (NPCs) are capable of self-proliferating and differentiating into the three major cell lineages of central nervous system (CNS), and has the potential for replacement of lost or dysfunctional neurons or glial cells. Stem cell replacement therapy may 1 day become a promising strategy for CNS injuries and neurodegenerative disorders. However, the limited regenerative capacity of both endogenous and grafted NPCs is attributed to the 
inhibition of NPC proliferation and differentiation in situ by local environmental factors. The proliferation and differentiation of NPCs are determined by the effects of extrinsic and intrinsic signals coming from substrates, medium components and several complex interactions among cells. Therefore, a better understanding of the role of the molecular environment to NPC neurogenesis may be crucial for developing stem cell therapy.

Several proteins associated with CNS myelin possess axon growth inhibiting properties. These include NogoA [1], myelin-associated glycoprotein (MAG) [2], and oligodendrocyte myelin glycoprotein (OMgp) [3]. All three bind the Nogo66 receptor (NgR1) [4] and the paired immunoglobulin-kuje receptor B (PirB) [5] to mediate their inhibitory influence. Multiple lines of evidence suggest that the myelin proteins and NgR1 may affect NPC activities in addition to the effects on axon regeneration. Besides being expressed in the adult neurons and weakly in adult nonneuronal cells, $\mathrm{NgR} 1$ is also expressed in the spinal cord, the brain of chicken and human embryo [6] and in the NPCs derived from rat spinal cords [7]. NogoA is expressed in neurons in a variety of areas of both fetal and adult human and rat brains [8]. It is also expressed in oligodendrocyte progenitor cells [9]. NogoA promoted NPCs to differentiate to the glial lineage while inhibiting their differentiation into neurons [10]. Nogo-P4 (the active segment of Nogo-66) inhibited the differentiation of NPCs derived from rat spinal cords [7]. Since the expression levels of NogoA, MAG and OMgp are upregulated after CNS injury, they may be important factors for NPC neurogenesis.

The NgR1 antagonist, recombinant rat soluble NgR-Fc fusion protein [11], effectively blocked the interaction of myelin proteins with $\mathrm{NgR} 1$ and has been shown to promote recovery in rodent models of CNS injuries [12-16]. Notch1 is an important signaling pathway in the embryogenesis, hematogenesis and the differentiation of NPCs during development $[17,18]$. Upon activation by Notch ligands, Notch intracellular domain (NICD) is cleave, released from the whole receptor, and activated transcription of its downstream target genes [19]. So far, Hairy/ Enhancer of Split (Hes) genes appears to be the primary downstream mediators of Notch signaling. Among them, Hes5 is considered to be an essential effector of Notchmediated activity [20]. In the developing brain, activated Notch signaling maintains NPCs and promotes proliferation of neural progenitors $[21,22]$. We hypothesize that NogoA and NgR1 are involved in the proliferation of NPCs and the NgR antagonist, sNgR-Fc, may affect NPC proliferation. In this study, we examined the expression of NogoA in NPCs and investigated whether sNgR-Fc promotes the proliferation of NPCs via Notch signaling pathway in vitro.

\section{Methods}

Preparation of NgR1-Fc Protein

The form of sNgR-Fc used for this study, AA-rNgR(310)$\mathrm{rFc}$ [12], is an improved variant form of the NgR-ecto-Fc fusion protein reported previously [15]. This protein comprises a 310 amino acid fragment of rat $\mathrm{NgR} 1$ fused to a rat IgG1 Fc fragment, in which Cys266 and Cys309 were replaced with alanine residues in order to eliminate heterogenous disulfide bonds [23]. The construct was expressed in Chinese hamster ovary cells, protein was purified, and binding to Nogo66, OMgp, and MAG was verified using previously established methods [15]. This modified protein inhibits the Nogo66-NgR interaction and promotes neurite growth of rat dorsal root ganglia and cerebellar granule neurons in vitro with similar potency as the unmodified sNgR-Fc [12].

Primary Neurosphere Culture, Differentiation and Immunocytochemistry

The procedures for isolation of embryonic NPCs have been described previously [24]. The hippocampus of embryonic day (E) 16 embryo of Sprague-Dawley (SD) rats from Laboratory Animal Unit, The University of Hong Kong was dissected, rinsed in cold CMF-HBSS and dissociated mechanically. The cells were collected by centrifugation and resuspended in Dulbecco's modified Eagle's Medium/ HamF12 (DMEM/F12) supplemented with epidermal growth factor (EGF; $20 \mathrm{ng} / \mathrm{ml}$, Gibco, CA, USA), basic fibroblast growth factor (bFGF, $20 \mathrm{ng} / \mathrm{ml}$, Sigma, MO, USA), B27 supplement ( $2 \%$, Gibco, CA, USA), N2 supplement (1\%, Gibco, CA, USA), penicillin $(50 \mathrm{U} / \mathrm{ml})$, and streptomycin $(50 \mu \mathrm{g} / \mathrm{ml})$. The cells were adjusted to $1 \times 10^{5}$ cells $/ \mathrm{ml}$ for cell culture. Half of the culture medium was replaced every 3 days. To identify the cultured cells, some of neurospheres after cultured for 7 days were plated on poly-L-lysine-coated coverslips and grown in culture medium. After neurospheres were attached on the coverslips $(2 \mathrm{~h})$, they were fixed with $4 \%$ paraformaldehyde (PFA) for $20 \mathrm{~min}$, washed, permeated in $0.25 \%$ Triton-X100/phosphate buffered saline (PBS) and blocked with $10 \%$ goat serum. Cells were then incubated with mouse anti-Nestin (1:100, Santa Cruz Biotechnology, CA, USA) at $4^{\circ} \mathrm{C}$ for $16 \mathrm{~h}$. After washing, the cells were incubated with a fluorescent Alexa 568-conjugated secondary antibody (1:400, Molecular Probes, CA, US) for $2 \mathrm{~h}$ at room temperature. Cell nuclei were counterstained with 4',6-diamidino-2-phenylindole (DAPI, Sigma, MO, USA). The above neurospheres were harvested, dissociated and plated as described above, but in culture medium without EGF and bFGF for initiating and promoting differentiation. 
After 3 days of differentiation, the cells were immunostained using mouse anti- $\beta$ III-tubulin antibody (Sigma, MO, USA) for undifferentiated neural progenitor cells, rabbit anti-glial fibrillary acidic protein (GFAP) $(1: 1,000$; Chemicon, Temecula, California, USA) for astrocytes or mouse anti-Rip (1:50, Abcame, CB, UK) for oligodendrocyte, mouse anti- $\beta$ III-tubulin antibody (1:1,000, Sigma, MO, USA) for neurons. The cells were incubated with a fluorescent Alexa 488 or 568-conjugated secondary antibody (1:400, Molecular Probes, CA, US) and Cell nuclei were counterstained with DAPI (Sigma, MO, USA).

In order to examine the expression of NogoA and Notch1 in NPCs, the above neurospheres were dissociated and seeded onto poly-L-lysine-coated coverslips in $1 \times 10^{4}$ cells/well with the above medium. The cells were then double-immunostained using rabbit anti-NogoA (1:100, Santa Cruz, Biotechnology, CA, USA) and mouse anti-Nestin (1:100, Santa Cruz Biotechnology, CA, USA) or rabbit anti-Notch1 (1:100, Upstate, Temecula, CA, USA) and mouse anti-Nestin antibodies as described above.

Proliferation Assay for Neurospheres and NPCs in Vitro

After 7 days in culture, the neurospheres were treated with $0.25 \%$ trypsin for $10 \mathrm{~min}$ and then mechanically dissociated. The dissociated NPCs were seeded onto poly-Llysine-coated coverslips in $1 \times 10^{4}$ cells/well with the $500 \mu \mathrm{l}$ medium. sNgR-Fc of 50,500 , or $1,000 \mathrm{ng} / \mathrm{ml}$ was added to the cultures, respectively. Untreated cultures were used as control. In order to examine whether the sNgR-Fc promotes the proliferation of NPCs by inhibiting the effects of CNS myelin proteins, recombinant rat MAG-Fc chimera (200 ng/ml, R \& D Systems, Inc, MN, USA) was added to the medium to neutralize sNgR-Fc (500 ng/ml). To confirm the role of Notch signaling pathway in the proliferation activity of sNgR-Fc on the NPCs, we used a Notch1 antagonist, MW167 ( $\gamma$-Secretase Inhibitor II, $10 \mu \mathrm{mol} / 1$, Calbiochem, CA, USA), to block Notch activity.

\section{Counting the Total Cell Number for the Proliferation Assay}

To analyze neurosphere growth, the volume of living neurospheres was measured using an inverted microscope (Axiovert 100, Carl Zeiss, Jena, Germany) and ImageJ software (National Institute of Health, USA). In order to determine the cell number, the treated spheres were collected at 24, 48 and $72 \mathrm{~h}$ after plating and the cells were counted as described [25]. The neurospheres in one well were trypsinized with $2 \mathrm{ml}$ of $1 \times$ typsin-EDTA (ethylenediaminetetraacetic acid) $(0.05 \%$ trypsin, $0.02 \%$ EDTA-4Na)
(GIBCO, Invitrogen corporation, CA, USA) for $2 \mathrm{~min}$. Trypsin-EDTA was then removed and cells were incubated at $37^{\circ} \mathrm{C}$ for another $2 \mathrm{~min}$. After incubation, cells were suspended in $1 \mathrm{ml}$ medium and single-cell suspensions at $2-5 \times 10^{5}$ cells $/ \mathrm{ml}$ were obtained. Ten $\mu \mathrm{l}$ cell suspension was loaded to the chamber of hemocytometer by capillary action and number of cells were counted using microscope. A total 72 cultures (6 cultures in each concentration of $\mathrm{sNgR}-\mathrm{Fc}$ and control group every day) was used for the total cell number counting. The volume of living neurospheres after different treatments was measured using an inverse confocal microscope (LSM 510 META; Carl Zeiss, Oberkochen, Germany) and ImageJ software (National Institute of Health, USA) as previous report [25].

\section{BrdU Labeling for the Cells of Proliferation Assay}

For bromodeoxyuridine (BrdU) labeling, $72 \mathrm{~h}$ after the above treatments, $10 \mu \mathrm{M}$ BrdU was applied to the cultures for $2 \mathrm{~h}$ to label the nuclei of proliferating cells. Then, immunocytochemistry on the cultures was performed to detect BrdU positive cells after fixation with 4\% PFA. Briefly, the cultures were denatured in $2 \mathrm{~N} \mathrm{HCl}$ at $37^{\circ} \mathrm{C}$ for $30 \mathrm{~min}$ and rinsed in $0.1 \mathrm{M}$ borax acid buffer $(\mathrm{pH} \mathrm{8.5)}$ at room temperature for $10 \mathrm{~min}$. Then, they were blocked with $1 \%$ bovine serum albumin, $10 \%$ normal goat serum, and $0.3 \%$ Triton X-100 in $0.01 \mathrm{M}$ PBS for $1 \mathrm{~h}$ at room temperature. After that, cultures were incubated with mouse anti-BrdU antibody (1:1,000, Sigma, MO, USA) overnight at $4^{\circ} \mathrm{C}$ and incubated with fluorescent Alexa Fluor $^{\circledR} 488$ or 568 goat anti-mouse secondary antibody (1:400, Molecular Probes, CA, USA) for $2 \mathrm{~h}$ at room temperature. Finally, the nuclei of all the cells were counterstained with DAPI (Sigma, MO, USA). A total thirty-six cultures (six cultures in each group) was used for the proliferation assay.

After immunostaining, the number of immunopositive cells in each culture was counted using a $\times 20$ objective. Five visual fields were selected on the edge of up, down, right and left, and the central of each slide, which is a total of 30 visual fields were counted for each parameter. DAPI-stained cells, representing the total cell number, and BrdU-immunoreactive cells in each field were counted. Percentages for each antibody-immunoreactive cells were calculated.

Western Blotting for Notch1 and Hes 5

Cells treated with sNgR-Fc, MAG or MW167 were plated at $1.0 \times 10^{6}$ cells $/ \mathrm{ml}$ in flasks and were collected $72 \mathrm{~h}$ later for Notch1 analyses using Western blotting. The cells were trypsinized, washed in cold $0.01 \mathrm{M}$ PBS and collected 
as pellets by centrifugation at $1,500 \mathrm{rpm}$ for $5 \mathrm{~min}$. The cell pellet was then resuspended in $80 \mu \mathrm{l}$ of radioimmunoprecipitation (RIPA) buffer [1\% Nonidet P-40, $0.5 \%$ sodium deoxycholate, $0.1 \%$ SDS, $10 \mu \mathrm{g} / \mathrm{ml}$ PMSF (phenylmethylsulfonyl fluoride)], $20 \mu \mathrm{g} / \mathrm{ml}$ Aprotinin, $10 \mu \mathrm{g} / \mathrm{ml}$ Leupeptin, $100 \mathrm{mM}$ sodium orthovanadate, in PBS and incubated on ice for $30 \mathrm{~min}$. The protein lysate was then centrifuged at $13,500 \mathrm{rpm}$ for $20 \mathrm{~min}$ at $4^{\circ} \mathrm{C}$. The supernatant was collected and measured for the protein concentration using the Dc Protein Assay Kit (Bio-Rad, Hercules, CA, USA). A $20 \mu \mathrm{g}$ aliquot of protein from each sample was subjected to 8-12.5\% SDS-polyacrylamide gel electrophoresis and transferred onto PVDF membrane. The membranes were blocked with 5\% nonfat dry milk and $2 \%$ bovine serum albumin in Tris-buffered saline containing $0.1 \%$ Tween 20 (TBST) for $1 \mathrm{~h}$ at room temperature. Incubation with rabbit anti-Notch1 (1:1,000, Millipore, Temecula, CA, USA) antibody against NICD or rabbit antiHes 5 (1:1,000, Abcam, CB, UK) was performed for $16 \mathrm{~h}$ at $4^{\circ} \mathrm{C}$. After washing, the membranes were incubated with horseradish peroxidas-conjugated goat anti-rabbit antibody (1:2,000, Dako, Denmark) in 5\% non fat dry milk and 2\% bovine serum albumin in TBST for $1 \mathrm{~h}$ at room temperature and immunoreactive proteins were detected using the enhanced chemiluminescence method (ECL, Amersham, Piscataway, NJ, USA). Protein loading was controlled using a goat against anti-actin antibody $(1: 2,000, \mathrm{C}-11$, Santa Cruz Biotechnology, CA, USA). The experiments for Western blotting were repeated 3 times, and representative data is shown.

\section{TUNEL Staining for Apoptosis}

Neurospheres were prepared, cultured and collected as described above, with either $500 \mathrm{ng} / \mathrm{ml} \mathrm{sNgR-Fc}$ or neurosphere medium alone. After fixation, an In Situ Cell Death Detection Kit FITC (Roche, Mannheim, Germany) was used for immunocytochemical detection of apoptosis, based on labeling of DNA strand breaks (TUNEL technology) according to the manufacturer's instructions. Fluorescein isothiocyanate (FITC) fluorescence was monitored using an inverse confocal laser scanning microscope. As positive control, neurospheres were treated with DNAse (2,000 U/ml, Sigma, Deisenhofen, Germany). As negative control, labeling solution containing FITC was used.

\section{Data and Statistical Analysis}

The values presented are mean \pm SEM. Statistical analysis was performed using one-way analysis of variance (ANOVA) followed by post-hoc tests (Student-NeumanKeuls) for comparisons of results obtained from more than two groups. Data were analyzed statistically with the software SPSS 12.0. $P<0.05$ was considered statistically significant.

\section{Results}

Characterization of Neural Progenitor Cells Derived from the Hippocampus

In the presence of epidermal growth factor and basic fibroblast growth factor, the hippocampus-derived neural progenitor cells proliferated quickly to form small clusters and then to larger neurospheres floating within the culture medium in 3-7 days. Immunocytochemistry revealed that the cells in neurospheres were positive for Nestin (Fig. 1a-c). The differentiation potential of NPCs was evaluated 3 days after mitogens were removed and were cultured in the presence of $10 \%$ fetal bovine serum (FBS). Neuronal cells that had differentiated from the neurospheres were confirmed by their immunoreactivity for $\beta$ III-Tubulin (Fig. 1d-f). The differentiated cells were also immunoreactive for glial fibrillary acidic protein (GFAP) (for astrocytes) (Fig. 1g-i) and Rip (for oligodentrocytes) (Fig. 1j-1). It showed that these neurospheres could differentiate into neurons, oligodentrocytes and astrocytes simultaneously.

\section{NogoA was Expressed in NPCs in Vitro}

Cultured NPCs stained strongly for NogoA (Fig. 2). We also confirmed that NogoA was coexpressed with Nestin (Fig. 2a-d). The proportion of NogoA $+/ \mathrm{Nestin}+$ was $98.2 \pm 1.23 \%$.

\section{sNgR-Fc Activated the Proliferation of NPCs}

We next investigated the effect of $\mathrm{sNgR}-\mathrm{Fc}$ on the proliferation of NPCs in culture. NPCs were treated for up to 3 days with $\mathrm{sNgR}-\mathrm{Fc}$ in different concentrations $(0,50$, $500 / \mathrm{ml}$ and $1,000 \mathrm{ng} / \mathrm{ml}$ ). There was significant difference for the treatment of $\mathrm{sNgR}-\mathrm{Fc}$ on day $1[F(3,20)=2.341$; $P<0.01]$, day $2[F(3,20)=4.437 ; P<0.01]$ and day 3 $[F(3,20)=6.674 ; \quad P<0.001]$. There was significant increase in the total number of cells in the $500 \mathrm{ng} / \mathrm{ml}$ and $1,000 \mathrm{ng} / \mathrm{ml}$ groups compared to the control group on day 1,2 and 3 respectively (Fig. $3 a, P<0.01$ ). A significant increase in volume of the neurospheres was also found after the treatment of $\mathrm{sNgR}-\mathrm{Fc}[F(3,20)=8.342$; $P<0.001$ ] (Fig. 3b). Representative photomicrographs of neurospheres at 3 days are shown in Fig. 3c (for control) and Fig. 3d (for $500 \mathrm{ng} / \mathrm{ml} \mathrm{sNgR}-\mathrm{Fc}$ ). In order to evaluate the effects of sNgR-Fc on the induction of apoptosis, the cells were treated with $\mathrm{sNgR}-\mathrm{Fc}$ for 3 days and analyzed 


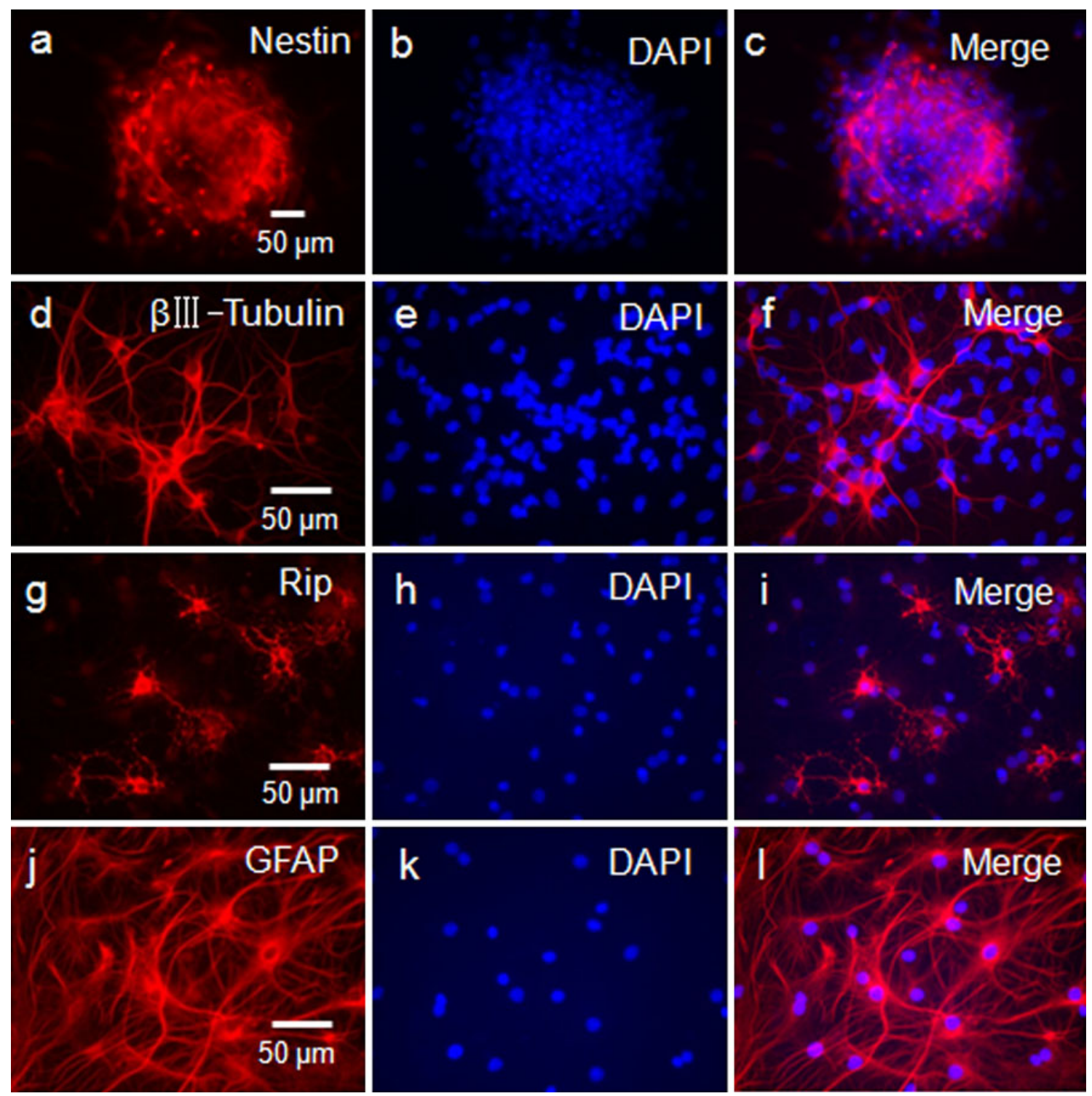

Fig. 1 Identification of the cultured neural progenitor cells. a-c The neurosphere expressed nestin positively. d-f Neurospheres could differentiate into $\beta$ III-Tubulin ${ }^{+}$cells. $\mathbf{g}-\mathbf{i}$ Neurospheres could differentiate into $\mathrm{Rip}^{+}$cells. $\mathbf{j}-\mathbf{l}$ Neurospheres could differentiate into
GFAP (glial fibrillary acidic protein) positive cells. Cultured neural progenitor cells were counterstained with $4^{\prime}$,6-diamidino-2-phenylindole (DAPI)
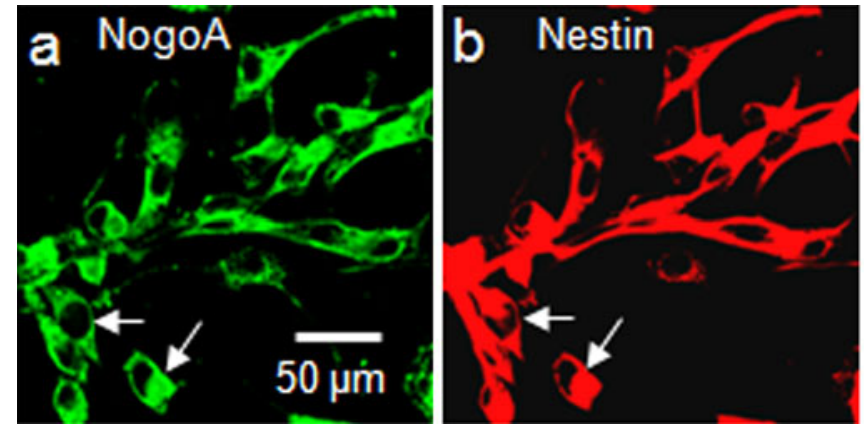

Fig. 2 The expression of NogoA in the cultured neuronal progenitor cells. NogoA expressed in neural progenitor cells (arrows). NogoA staining (green) (a), Nestin staining (red) (b) demonstrates the

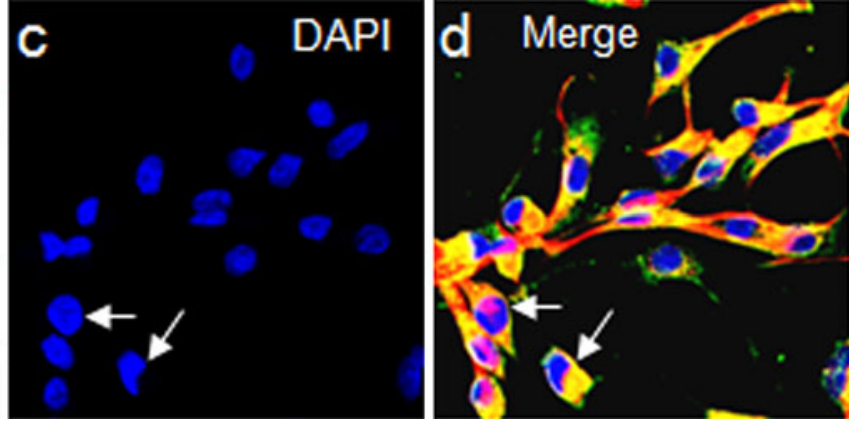

co-localization of NogoA and Nestin in neural progenitor cells (d) (arrows). The nucleus was counterstained with DAPI $\left(4^{\prime}, 6-\right.$ diamidino-2-phenylindole) (c) 
for apoptosis using a TUNEL assay (Fig. 3e). DNAse treatment as a positive control resulted in nearly $75 \%$ TUNEL-positive nuclei. Label solution as a negative control gave no positive signal. Few apoptotic nuclei were detected and there was no difference between the control and $\mathrm{sNgR}-\mathrm{Fc}$-treated groups. These results suggest that the effect of $\mathrm{sNgR}-\mathrm{Fc}$ on the increase of NPCs number might be a result of proliferation, and not because of the reduction of cells through apoptosis.

a

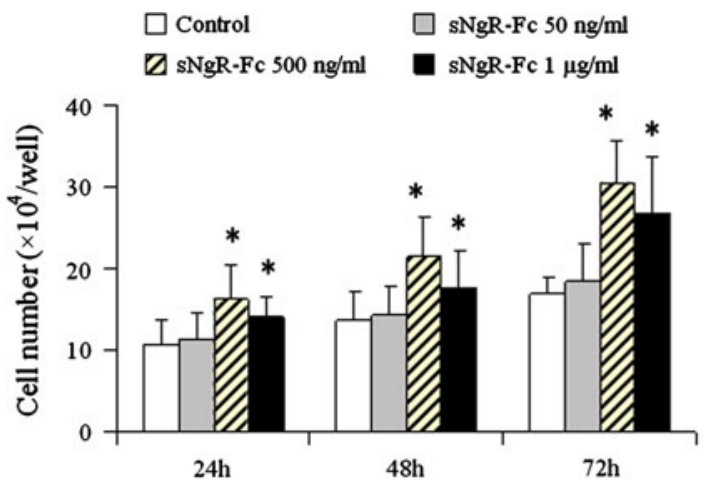

b

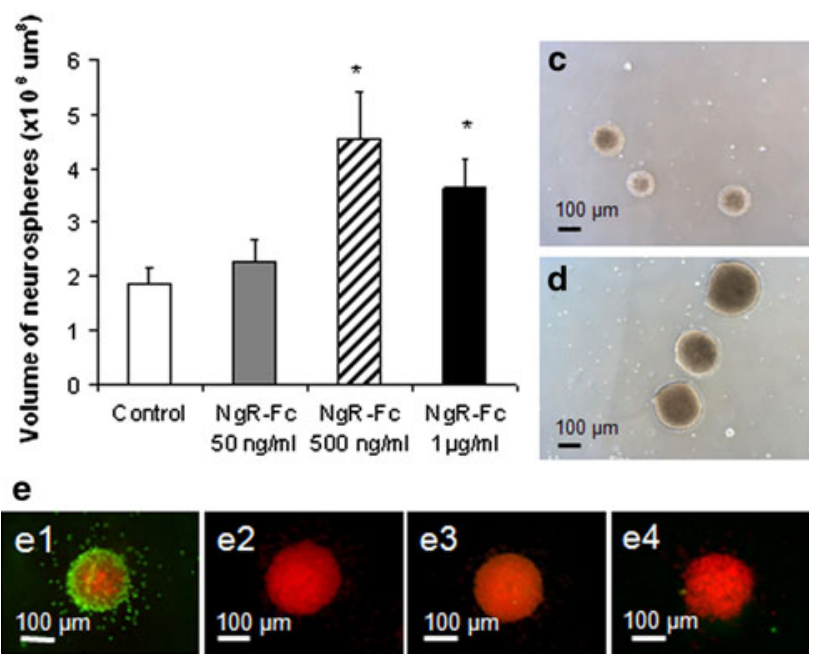

Fig. 3 Enhanced proliferation of neural progenitor cells with the treatment of $\mathrm{sNgR}-\mathrm{Fc}$ in vitro. Neural progenitor cells (NPCs) were treated for up to 3 days with different concentration of $\mathrm{sNgR}-\mathrm{Fc}(0$, 50,500 and $1,000 \mathrm{ng} / \mathrm{ml}$ ). The total cell number was quantified. a There was an increase in the number of the cells with the treatment of sNgR-Fc. $P<0.01$ compared to control group in the same time point. b Quantification of neurosphere volume. sNgR-Fc-treated neurospheres show significantly increased volume compared to untreated neurospheres $(* P<0.01)$, six cultures for each group. c-d Photographs of neurospheres, 3 days after plating, show larger neurospheres after $\mathrm{sNgR}-\mathrm{Fc}$ treatment $(500 \mathrm{ng} / \mathrm{ml})(\mathrm{d})$ than in control neurospheres (c). e NgR-Fc rarely triggers apoptosis in NPCs. Apoptosis was detected using TUNEL with FITC-conjugated dUTP for the neurospheres. Positive control cultures were treated with DNAse I to generate nicked DNA (e1). Terminal deoxynucleotidyl transferase was omitted for negative controls $(e 2)$. Few apoptotic nuclei were detected and there was no difference between the control (e3) and sNgR-Fc-treated (e4) groups
Next, we examined whether the increased new cells were derived from NPCs. We analyzed progenitor cell proliferation with BrdU incorporation. This technique has been extensively used to measure DNA replication during proliferation of mammalian cells. We found that there was significant different in the cell proliferation with BrdU incorporation $[F(5,24)=12.465 ; P<0.001]$. The amount of BrdU incorporation rose and was higher in $500 \mathrm{ng} / \mathrm{ml}$ and $1,000 \mathrm{ng} / \mathrm{ml}$ groups compared to the control (Fig. 4a$\mathrm{d}, \mathrm{g}, P<0.01)$. Here we also examined the effect of sNgR$\mathrm{Fc}$ on the proliferation of NPCs via counting DAPI positive cells. The total number of DAPI showed that there was more cells after sNgR-Fc treatment $(500 \mathrm{ng} / \mathrm{ml}$ or $1 \mu \mathrm{g} / \mathrm{ml})$ $[F(5,24)=11.128 ; P<0.001]$ (Fig. 4h)

MAG Inhibits the Proliferative Effect of sNgR-Fc on NPCs

In order to investigate the mechanism by which $\mathrm{sNgR}-\mathrm{Fc}$ promotes the proliferation of NPCs, we added MAG into the culture medium. The $\mathrm{NgR}-\mathrm{Fc}$ fusion protein can directly bind with MAG-Fc [15]. Using the BrdU incorporation technique, we found that the ability of sNgR-Fc $(500 \mathrm{ng} / \mathrm{ml})$ to promote the ratio of BrdU incorporation was clearly inhibited after the administration of MAG-Fc (Fig. 4e, g). It suggests that $\mathrm{sNgR-Fc}$ may promote the proliferation of NPCs by inhibiting the action of myelin proteins such as MAG.

\section{sNgR-Fc Activated Notch1 in NPCs}

We investigated the level of Hes5 and NICD in $\mathrm{sNgR}-\mathrm{Fc}$ treated NPCs using Western blotting (Fig. 5a). Significant differences among Hes $5[F(5,12)=5.624 ; P<0.001]$ and $\operatorname{NICD}[F(5,12)=8.366 ; P<0.001]$ levels were subsequently revealed by ANOVA analysis. The levels of Hes5 were higher for $\mathrm{sNgR}-\mathrm{Fc}(500 \mathrm{ng} / \mathrm{ml})$ compared to control treatment. The levels of NICD were higher for sNgR-Fc $(50 \mathrm{ng} / \mathrm{ml})$ compared to control treatment, peaked for $500 \mathrm{ng} / \mathrm{ml} \mathrm{sNgR-Fc}$ treatment and then declined slightly in the $1,000 \mathrm{ng} / \mathrm{ml} \mathrm{sNgR-Fc}$ group. MW167, an inhibitor of the Notch1 signaling pathway, significantly blocked the activation of Notch1 by sNgR-Fc (Fig. 5a, b). Using the BrdU incorporation technique, we found that MW167 significantly inhibited the ability of sNgR-Fc $(500 \mathrm{ng} / \mathrm{ml})$ to promote the ratio of BrdU incorporation (Fig. 4f, g). Furthermore, we found that the administration of MAG-Fc blocked the activation of Notch1 with the treatment of sNgR-Fc (Fig. 5a, b). These data further suggest that $\mathrm{sNgR}-\mathrm{Fc}$ may promote the proliferation of NPCs by inhibiting the activity of myelin proteins. We next demonstrated that Notch1 was coexpressed with Nestin in the NPCs using immunocytochemistry. Figure 5e, f shows 

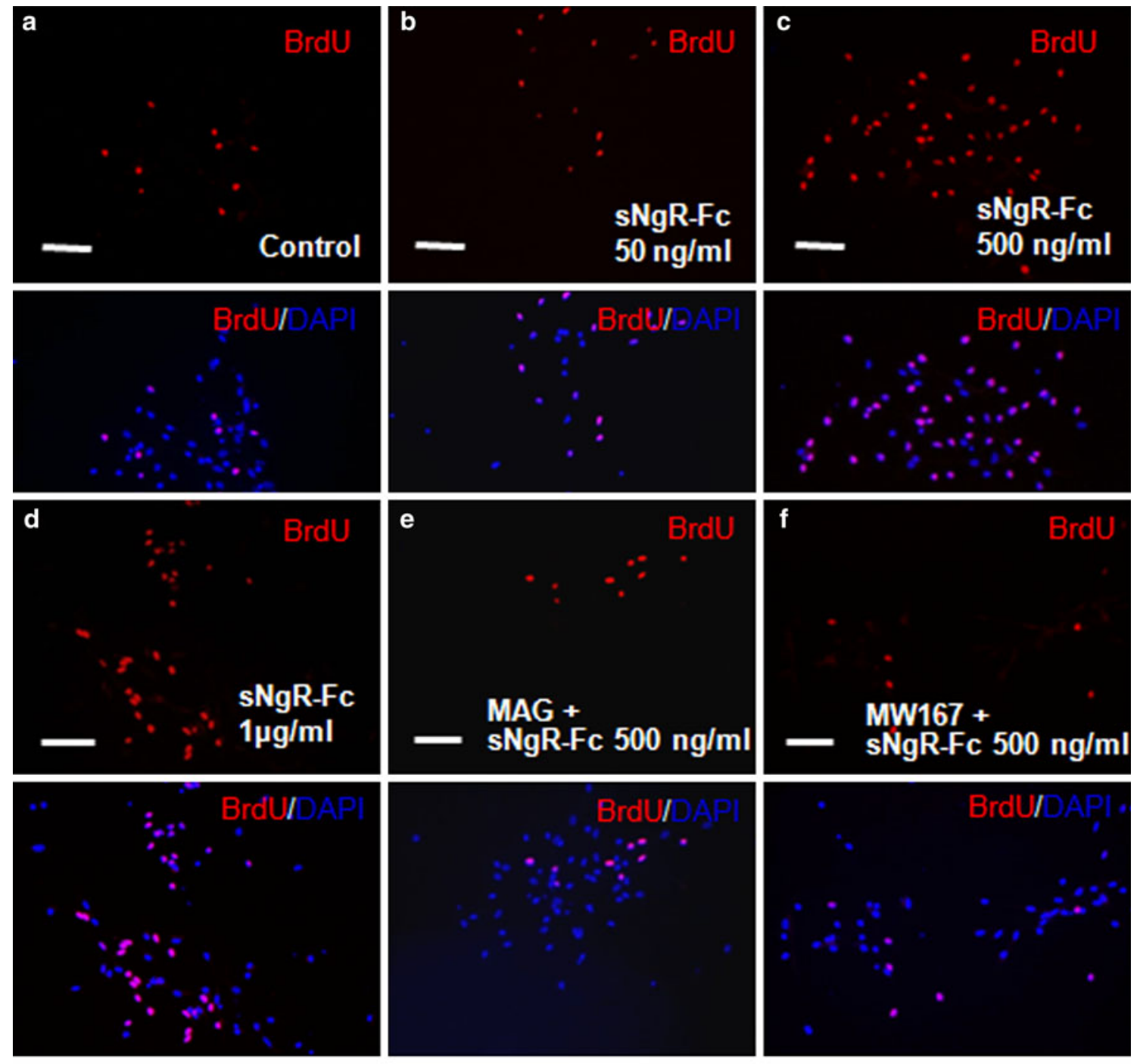

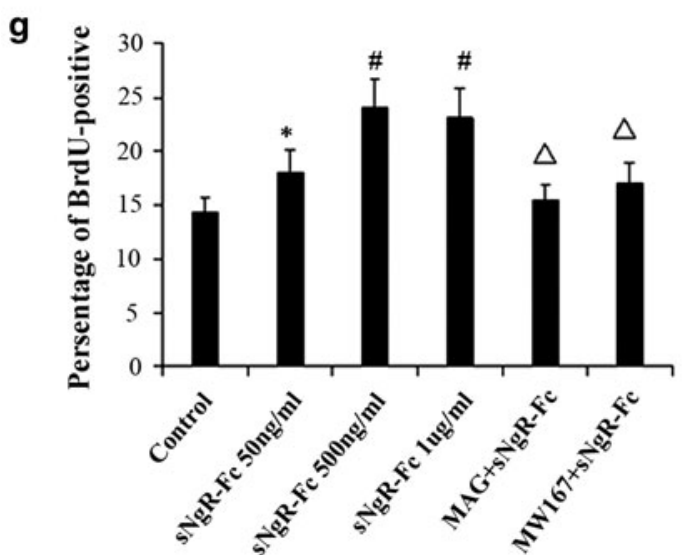

Fig. 4 sNgR-Fc increased bromodeoxyuridin incorporation. Merged images of bromodeoxyuridin (BrdU) and 4',6-diamidino-2-phenylindole (DAPI). The NPCs were treated as described below for 3 days and then pulsed with BrdU $(10 \mu \mathrm{M})$ for $2 \mathrm{~h}$. a The control group, cultured neural progenitor cells (NPCs) received no further treatment. b-d Cultured NPCs received treatment of different dosage of $\mathrm{sNgR}-\mathrm{Fc}$. e Cultured NPCs received treatment with $\mathrm{sNgR}-\mathrm{Fc}(500 \mathrm{ng} / \mathrm{ml})$ plus myelin-associated glycoprotein (MAG). f Cultured NPCs received treatment with sNgR-Fc h

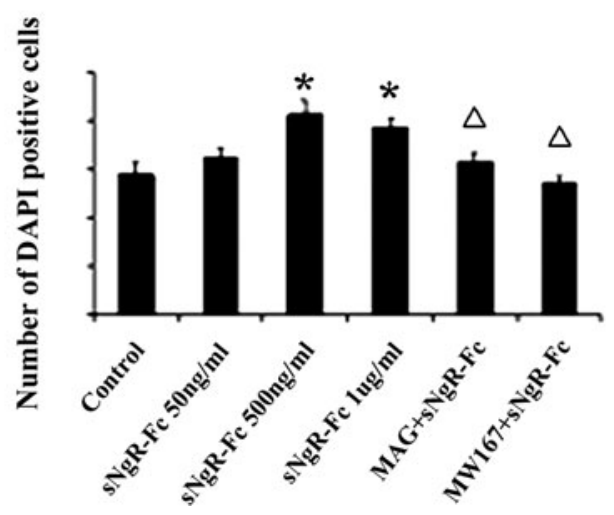

(500 ng/ml) plus MW167, a Notch1 inhibitor. sNgR-Fc increased the ratio of BrdU-positive neural progenitor cells in dosage-dependent manners, while MAG or MW167 decreased such increased ratio of BrdU incorporation. $\mathbf{g}$ A percentage of BrdU-positive cells in total number of cells with different treatments. $\mathbf{h}$ The total number of DAPI positive cells five visual fields in different groups. In $\mathbf{g}, \mathbf{h},{ }^{*} P<0.05,{ }^{\#} P<0.01$ compared with control group. Open triangle $P<0.01$ compared to $500 \mathrm{ng} / \mathrm{ml}$ group. Six cultures for each group (Mean \pm SEM) 
a
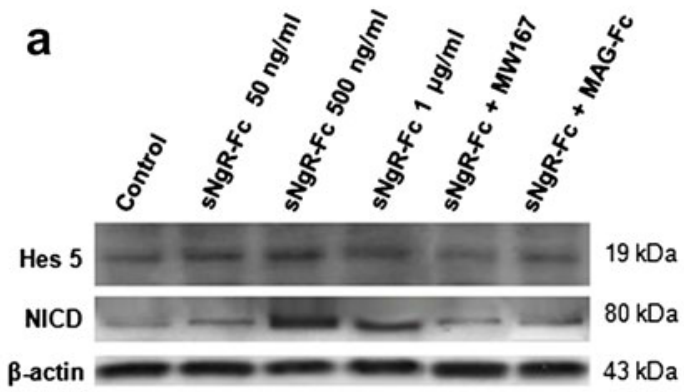

Notch1

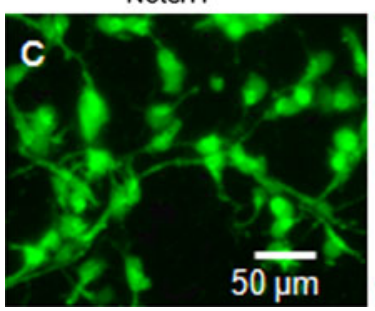

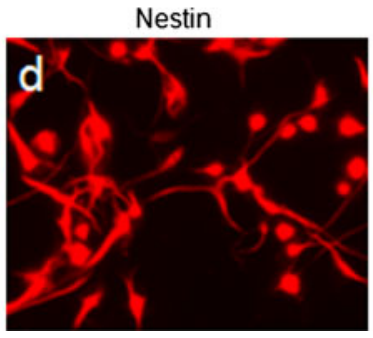

Fig. 5 Notch 1 expression in neural progenitor cells. a The treated neural progenitor cells (NPCs) with sNgR-Fc (500 ng/ml), MAG (myelin-associated glycoprotein) or MW167 (a Notch1 inhibitor) were used for Notch1 activation using Western blotting. b Quantitative analysis of Western blotting. The levels of NICD (Notch intracellular domain) and Hes 5 were increased with the different dosages of $\mathrm{sNgR}-\mathrm{Fc}$, but were reversed by the administration of MAG

representative photomicrographs of Notch1 immunolabelling in NPCs after the treatment of sNgR-Fc $(500 \mathrm{ng} / \mathrm{ml})$.

\section{Discussion}

The present study aimed to elucidate whether NgR1 fusion protein promotes the proliferation of NPCs and to examine the possible signaling mechanisms involved. Our results demonstrated that: (1) NogoA was expressed in cultured NPCs; (2) sNgR-Fc promoted NPC proliferation; (3) MAG reversed the proliferative effect of $\mathrm{sNgR}-\mathrm{Fc}$ on NPCs. (4) sNgR-Fc activated Notch1 and a Notch1 inhibitor reversed the effect of $\mathrm{sNgR-Fc}$ on NPC proliferation.

\section{Effect of NgR1 Fusion Protein on NPC Proliferation}

$\mathrm{NgR} 1$ is associated with axon regeneration and neurite growth. NgR1 is expressed in neurons in different CNS regions, such as the cortex, subventricular zone and dentate subgranular zone; and upregulated after brain ischemic injury [26]. In this study we identified that the NPCs in the neurosphere and the single NPC strongly expressed NgR1. The NgR1 ecto-domain, $\mathrm{sNgR} 1$ is an NgR1 antagonist and

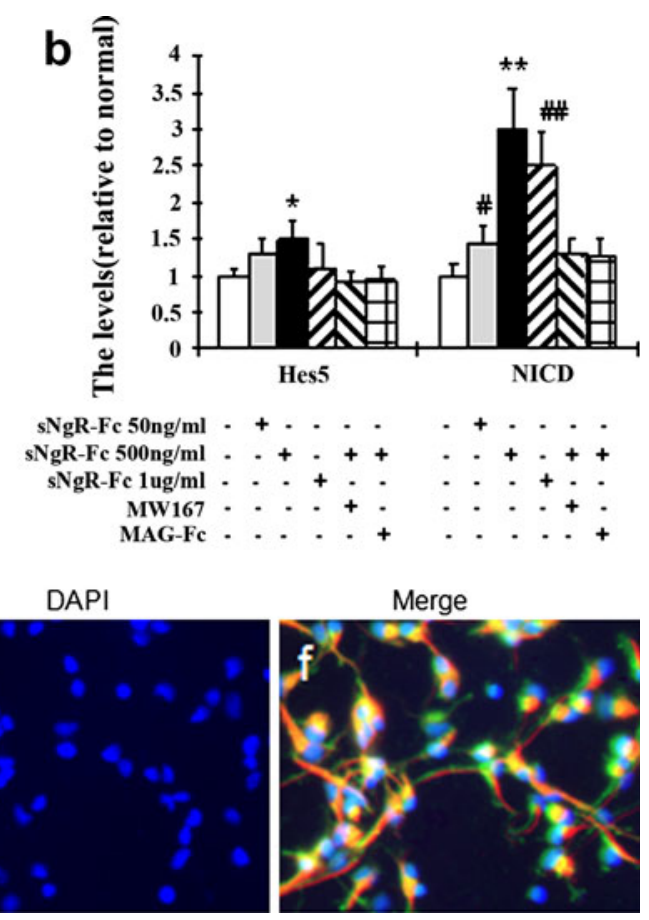

and MW167. $* P<0.05, * * P<0.01$ compared to the control group, MW167 and MAG-Fc groups. ${ }^{\#} P<0.05,{ }^{\# \#} P<0.01$ compared to the control group. The experiments were repeated 3 time. c-f Coexpression of Notch 1 (green) with Nestin (red) in the cultured NPCs after sNgR-Fc treatment $(500 \mathrm{ng} / \mathrm{ml})$. The nucleus was counterstained with DAPI (4',6-diamidino-2-phenylindole)

promotes axon regeneration after spinal cord injury [12, 15], stroke [14] or dorsal root rhizotomy [12, 16]. Our data suggest, in addition to axon regeneration, $\mathrm{sNgR}-\mathrm{Fc}$ also promotes the proliferation of NPCs.

Neural stem cells are characterized by the ability to undergo cell division and to differentiate into multiple cell types, e.g. neurons or glial cells. When stimulated by growth factors or cytokine, the NPCs could generate cleavage of asymmetry. Recently, much attention are focused on the therapeutic potential of neural stem cells to treat neurological disorders such as spinal cord injury [27, 28], stroke and Parkinson's disease [29, 30]. The factor(s) responsible for the proliferation and differentiation of NPCs has been the subject of intense investigation because identification of regulators of NPCs may allow for their eventual manipulation in the CNS as therapies to replace the injured CNS neurons. We have confirmed including the use of $\mathrm{BrdU}$ incorporation experiments, a significant increase in the number of the cells after $\mathrm{sNgR}$ $\mathrm{Fc}$ treatment. In addition, few apoptotic nuclei were detected in cells after sNgR-Fc-treatment. This suggests that the effect of sNgR-Fc on the increase in the number of NPCs may be linked to proliferative than anti-apoptotic mechanisms. 
Molecular Mechanism of sNgR-Fc on NPC Proliferation

We also examined the possible mechanism of the effect of $\mathrm{sNgR}-\mathrm{Fc}$ on the proliferation of NPCs. Nogo is expressed in three distinct isoforms, $\operatorname{NogoA}, \operatorname{NogoB}$ and NogoC, which is known as one of the myelin inhibitors that induces growth conecollapse and inhibit neurite outgrowth. Cell proliferation was inhibited significantly in the NogoC overexpressed PC12 cell which was used as a neuronal model [31]. If NPCs derived from the spinal cords of rats were allowed to differentiate in the presence of Nogo-P4, the average neurite length and the percentage of differentiated neurons were decreased [7]. NogoA was also reported to be expressed in the oligodendrocyte progenitor cells [9]. Much NogoA was observed in all of the development periods in rat hippocampus, and especially in the embryonic and neonatal rats [32]. In this study, we identified that there was NogoA expression in the NPCs. The NogoA expressed in NPCs has the potential to inhibit the proliferation of NPCs. The NgR1 has been shown to constitute a site of signal convergence for three axon inhibitory proteins found in CNS myelin [33]. Blockade of $\mathrm{NgR}$-dependent signaling by $\mathrm{sNgR} 1$ allows an assessment on the significance of summated inhibition from NogoA, MAG, and OMgp rather than inhibiting individual $\mathrm{NgR}$ ligands as there are several reported in the literature aside from myelin molecules such as LINGO-1, p75 and Troy. Since the expression of these molecules in NPCs are unclear or found at a later stage e.g. LINGO-1 [9], it is possible that $\mathrm{sNgR}-\mathrm{Fc}$ may promote the proliferation of NPCs by reversing the inhibitive effect of NogoA in particular that of the Nogo-66 loop. This is because MAG that also binds $\mathrm{NgR} 1$; eliminated the proliferative effect of sNgR-Fc. It will be interesting to verify if the amino-terminus of NogoA would also participate in this process. Reagents such as IN-1 antibody will be useful tools for delineating the NogoA epitopes involved in NPC proliferation.

\section{The Signaling Pathway for sNgR-Fc Stimulated NPC Proliferation}

Notch1 plays a pivotal role in the regulation of vertebrate neurogenesis [34]. During this process, Notch-mediated cell-cell interaction is essential for maintaining dividing cells and subsequent generation of cell type diversity. Upon activation by Notch ligands, NICD is cleave, released from the whole receptor, and activated transcription of its downstream target genes Hes 1 and Hes 5 [19]. Activation of Notch inhibits cellular differentiation, and abnormality of the Notch pathway leads to premature neuronal differentiation, the lack of some cell types, and severe defects of tissue morphogenesis [35]. Here we showed that the administration of sNgR-Fc activated Notch1, suggesting that $\mathrm{sNgR}-\mathrm{Fc}$ may stimulate the proliferation of NPCs by activation of Notch1 or its downstream molecules. These effects could be abolished by Notch1 inhibitor suggesting specificity. It will be of interest to test if the gammasecretase activity is directly related to NPC proliferation. Our data suggest that $\mathrm{sNgR}-\mathrm{Fc}$ stimulated NPC proliferation via activation of the Notch pathway.

Our data indicate that $\mathrm{sNgR}-\mathrm{Fc}$ promotes the proliferation of NPCs in vitro via the Notch1 signaling pathway. sNgR-Fc may provide an attractive therapeutic strategy of neuronal repair for treating CNS injuries and neurodegenerative disorders.

Acknowledgments This study was supported by funding from the Jessie Ho Professorship in Neuroscience, grants from the University of Hong Kong, National Basic Research Program of China (973Program, 2011CB707501), the Fundamental Research Funds for the Central Universities (21609101), NSFC (30801272, 81071030), Science and Technology Foundation of Guangdong Province, China (2010B031600089), and the Fundamental Research Funds for the Central Universities (09ykpy25, 09ykpy31). The funders had no role in study design, data collection and analysis, decision to publish, or preparation of the manuscript. Biogen Idec, Inc. provided the $\mathrm{sNgR}$ Fc in the study.

Open Access This article is distributed under the terms of the Creative Commons Attribution Noncommercial License which permits any noncommercial use, distribution, and reproduction in any medium, provided the original author(s) and source are credited.

\section{References}

1. Chen MS, Huber AB, van der Haar ME, Frank M, Schnell L, Spillmann AA et al (2000) Nogo-A is a myelin-associated neurite outgrowth inhibitor and an antigen for monoclonal antibody IN-1. Nature 403:434-439

2. Domeniconi M, Cao Z, Spencer T, Sivasankaran R, Wang K, Nikulina E et al (2002) Myelin-associated glycoprotein interacts with the Nogo66 receptor to inhibit neurite outgrowth. Neuron 35:283-290

3. Wang KC, Koprivica V, Kim JA, Sivasankaran R, Guo Y, Neve RL et al (2002) Oligodendrocyte-myelin glycoprotein is a Nogo receptor ligand that inhibits neurite outgrowth. Nature 417: 941-944

4. Fournier AE, GrandPre T, Strittmatter SM (2001) Identification of a receptor mediating Nogo-66 inhibition of axonal regeneration. Nature 409:341-346

5. Atwal JK, Pinkston-Gosse J, Syken J, Stawicki S, Wu Y, Shatz C et al (2008) PirB is a functional receptor for myelin inhibitors of axonal regeneration. Science 322:967-970

6. O'Neill P, Whalley K, Ferretti P (2004) Nogo and Nogo-66 receptor in human and chick: implications for development and regeneration. Dev Dyn 231:109-121

7. Wang F, Zhu Y (2008) The interaction of Nogo-66 receptor with Nogo-p4 inhibits the neuronal differentiation of neural stem cells. Neuroscience 151:74-81

8. Josephson A, Widenfalk J, Widmer HW, Olson L, Spenger C (2001) NOGO mRNA expression in adult and fetal human and rat nervous tissue and in weight drop injury. Exp Neurol 169:319-328 
9. Zhao XH, Jin WL, Ju G (2007) An in vitro study on the involvement of LINGO-1 and Rho GTPases in Nogo-A regulated differentiation of oligodendrocyte precursor cells. Mol Cell Neurosci 36:260-269

10. Wang B, Xiao Z, Chen B, Han J, Gao Y, Zhang J et al (2008) Nogo-66 promotes the differentiation of neural progenitors into astroglial lineage cells through mTOR-STAT3 pathway. PLoS One 3:e1856

11. GrandPre T, Li S, Strittmatter SM (2002) Nogo-66 receptor antagonist peptide promotes axonal regeneration. Nature 417:547-551

12. Harvey PA, Lee DH, Qian F, Weinreb PH, Frank E (2009) Blockade of Nogo receptor ligands promotes functional regeneration of sensory axons after dorsal root crush. J Neurosci 29:6285-6295

13. Ji B, Li M, Budel S, Pepinsky RB, Walus L, Engber TM et al (2005) Effect of combined treatment with methylprednisolone and soluble Nogo-66 receptor after rat spinal cord injury. Eur J Neurosci 22:587-594

14. Lee JK, Kim JE, Sivula M, Strittmatter SM (2004) Nogo receptor antagonism promotes stroke recovery by enhancing axonal plasticity. J Neurosci 24:6209-6217

15. Li S, Liu BP, Budel S, Li M, Ji B, Walus L et al (2004) Blockade of Nogo-66, myelin-associated glycoprotein, and oligodendrocyte myelin glycoprotein by soluble Nogo-66 receptor promotes axonal sprouting and recovery after spinal injury. J Neurosci 24:10511-10520

16. MacDermid VE, McPhail LT, Tsang B, Rosenthal A, Davies A, Ramer MS (2004) A soluble Nogo receptor differentially affects plasticity of spinally projecting axons. Eur J Neurosci 20:25672579

17. de la Pompa JL, Wakeham A, Correia KM, Samper E, Brown S, Aguilera RJ et al (1997) Conservation of the Notch signalling pathway in mammalian neurogenesis. Development 124:11391148

18. Hitoshi S, Alexson T, Tropepe V, Donoviel D, Elia AJ, Nye JS et al (2002) Notch pathway molecules are essential for the maintenance, but not the generation, of mammalian neural stem cells. Genes Dev 16:846-858

19. Schroeter EH, Kisslinger JA, Kopan R (1998) Notch-1 signalling requires ligand-induced proteolytic release of intracellular domain. Nature 393:382-386

20. Ohtsuka T, Ishibashi M, Gradwohl G, Nakanishi S, Guillemot F, Kageyama R (1999) Hes1 and Hes5 as notch effectors in mammalian neuronal differentiation. EMBO J 18:2196-2207

21. Nyfeler Y, Kirch RD, Mantei N, Leone DP, Radtke F, Suter U et al (2005) Jagged1 signals in the postnatal subventricular zone are required for neural stem cell self-renewal. EMBO J 24:3504-3515
22. Yoon K, Gaiano N (2005) Notch signaling in the mammalian central nervous system: insights from mouse mutants. Nat Neurosci 8:709-715

23. Weinreb PH, Wen D, Qian F, Wildes CP, Garber EA, Walus L et al (2010) Resolution of disulfide heterogeneity in Nogo receptor 1 fusion proteins by molecular engineering. Biotechnol Appl Biochem 57:31-45

24. Guo J, Zeng Y, Liang Y, Wang L, Su H, Wu W (2007) Cyclosporine affects the proliferation and differentiation of neural stem cells in culture. Neuroreport 18:863-868

25. Widera D, Mikenberg I, Elvers M, Kaltschmidt C, Kaltschmidt B (2006) Tumor necrosis factor alpha triggers proliferation of adult neural stem cells via IKK/NF-kappaB signaling. BMC Neurosci $7: 64$

26. Zhang S, Zhang Q, Zhang JH, Qin X (2008) Electro-stimulation of cerebellar fastigial nucleus (FNS) improves axonal regeneration. Front Biosci 13:6999-7007

27. Lu P, Jones LL, Snyder EY, Tuszynski MH (2003) Neural stem cells constitutively secrete neurotrophic factors and promote extensive host axonal growth after spinal cord injury. Exp Neurol 181:115-129

28. Guo JS, Zeng YS, Li HB, Huang WL, Liu RY, Li XB et al (2007) Cotransplant of neural stem cells and NT-3 gene modified Schwann cells promote the recovery of transected spinal cord injury. Spinal Cord 45:15-24

29. Schwarz SC, Wittlinger J, Schober R, Storch A, Schwarz J (2006) Transplantation of human neural precursor cells in the 6-OHDA lesioned rats: effect of immunosuppression with cyclosporine A. Parkinsonism Relat Disord 12:302-308

30. Yasuhara T, Matsukawa N, Hara K, Yu G, Xu L, Maki M et al (2006) Transplantation of human neural stem cells exerts neuroprotection in a rat model of Parkinson's disease. J Neurosci 26:12497-12511

31. Wu XN, Yao Q, Ju G (2000) The effects on survival and proliferation by overexpressed Nogo-C in PC12 cells. Chinese J Cell Biol 28:582-586

32. Mingorance A, Fontana X, Sole M, Burgaya F, Urena JM, Teng FY et al (2004) Regulation of Nogo and Nogo receptor during the development of the entorhino-hippocampal pathway and after adult hippocampal lesions. Mol Cell Neurosci 26:34-49

33. McGee AW, Strittmatter SM (2003) The Nogo-66 receptor: focusing myelin inhibition of axon regeneration. Trends Neurosci 26:193-198

34. Stump G, Durrer A, Klein AL, Lutolf S, Suter U, Taylor V (2002) Notch1 and its ligands Delta-like and Jagged are expressed and active in distinct cell populations in the postnatal mouse brain. Mech Dev 114:153-159

35. Kageyama R, Ohtsuka T (1999) The Notch-Hes pathway in mammalian neural development. Cell Res 9:179-188 